\title{
Glutathione Conjugation and Protein Adduction Derived from Oxidative Debromination of Benzbromarone in Mice ${ }^{\text {\} }$
}

\author{
Hui Wang, Wenbao Wang, Bowen Gong, Zedan Wang, Yukun Feng, Weige Zhang, Shaojie Wang, \\ Ying Peng, and Jiang Zheng
}

State Key Laboratory of Functions and Applications of Medicinal Plants, Key Laboratory of Pharmaceutics of Guizhou Province, Guizhou Medical University, Guiyang, Guizhou, People's Republic of China (J.Z.); and Wuya College of Innovation (H.W., Y.F., Y.P., J.Z.) and Key Laboratory of Structure-Based Drug Design and Discovery (Ministry of Education), School of Pharmaceutical Engineering (W.W., B.G., Z.W., W.Z., S.W.), Shenyang Pharmaceutical University, Shenyang, Liaoning, People's Republic of China.

Received April 8, 2019; accepted August 10, 2019

\begin{abstract}
Benzbromarone (BBR), a uricosuric agent, has been known to induce hepatotoxicity, and its toxicity has a close relation to cytochrome P450-mediated metabolic activation. An oxidative debromination metabolite of BBR has been reported in microsomal incubations. The present study attempted to define the oxidative debromination pathway of BBR in vivo. One urinary mercapturic acid (M1) and one glutathione (GSH) conjugate (M2) derived from the oxidative debromination metabolite were detected in BBR-treated mice after solid phase extraction. M1 and M2 shared the same chromatographic behavior and mass spectral identities as those detected in $\mathrm{N}$-acetylcysteine/GSHand BBR-fortified microsomal incubations. The structure of M1 was characterized by chemical synthesis, along with mass spectrometry analysis. In addition, hepatic protein modification that occurs at cysteine residues $\left(M^{\prime} 3\right)$ was observed in mice given BBR. The observed protein adduction reached its peak 4 hours after administration and occurred in a dose-dependent manner. A GSH conjugate derived from oxidative debromination of BBR was detected in livers of mice treated with BBR, and the formation of the GSH conjugate apparently took place earlier than the protein adduction.
\end{abstract}

In summary, our in vivo work provided strong evidence for the proposed oxidative debromination pathway of BBR, which facilitates the understanding of the mechanisms of BBR-induced hepatotoxicity.

\section{SIGNIFICANCE STATEMENT}

This study investigated the oxidative debromination pathway of benzbromarone (BBR) in vivo. One urinary mercapturic acid (M1) and one glutathione (GSH) conjugate (M2) derived from the oxidative debromination metabolite were detected in BBR-treated mice. M1 and M2 were also observed in microsomal incubations. The structure of M1 was characterized by chemical synthesis followed by mass spectrometry analyses. More importantly, protein adduction derived from oxidative debromination of BBR (M'3) was observed in mice given BBR, and occurred in dose- and time-dependent manners. The success in detection of GSH conjugate, urinary $\mathrm{N}$-acetylcysteine conjugate, and hepatic protein adduction in mice given BBR provided solid evidence for in vivo oxidative debromination of BBR. The studies allowed a better understanding of the metabolic activation of BBR.

\section{Introduction}

Benzbromarone (BBR) is a potent uricosuric therapeutically used as an antigout agent (Manger, 2015; Stamp et al., 2016). It is reported that both BBR and its major hydroxylation metabolite, 6-hydroxyBBR, are strong inhibitors to human uric acid transporter 1, which is responsible for urate reabsorption (Iwanaga et al., 2005; Nindita et al., 2010). However, BBR is not widely available due to concerns about serious idiosyncratic hepatotoxicity (Hautekeete et al., 1995; Suzuki et al., 2001; Arai et al., 2002; Haring et al., 2013).

Drug-induced liver injury (DILI) is one of the most important reasons for drug withdrawal from the market (Chen et al., 2014;

This work was supported in part by the National Natural Science Foundation of China [Grants 81373471, 81430086, and 81773813], the Natural Science Foundation of Liaoning Province [Grant 2015020738], and the Scientific Research Program of Hainan Province [Grant ZDYF2016143].

https://doi.org/10.1124/dmd.119.087460.

S This article has supplemental material available at dmd.aspetjournals.org.
Tolosa et al., 2018). The mechanisms underlying DILI remain unclear. It is generally accepted that cytochrome P450-mediated metabolic activation plays a key role in DILI (Guengerich, 2011; McEneny-King et al., 2017; Quintanilha et al., 2017). Currently, there are four possible metabolic pathways available for BBR. McDonald and Rettie (2007) first suggested that BBR was sequentially oxidized by CYP2C9 to a catechol which can be further oxidized to a reactive $o$-quinone intermediate identified as glutathione (GSH) conjugates in liver microsomal systems. Previous work from our laboratory revealed that BBR was metabolized to an epoxide intermediate(s) through the initial epoxidation of the benzofuran ring by CYP3A (Wang et al., 2016b). In our following studies, mercapturic acid excreted from urine and hepatic protein adduction derived from the epoxide intermediate(s) were observed in BBR-treated mice, which confirmed the epoxidation metabolism of BBR in vivo (Wang et al., 2016a,b). The correlation between metabolic epoxidation and hepatotoxicity of BBR was further determined by manipulating the structure of BBR through introduction of halogen atoms to the site of CYP3A metabolism

ABBREVIATIONS: Ar-H aromatic-H BBR, benzbromarone; DILI, drug-induced liver injury d doublet; ESI, electrospray ionization; GS, source gas; GSH, glutathione; IS, internal standard; LC-MS/MS, liquid chromatography coupled to tandem mass spectrometry; MRM, multiple reaction monitoring; MS, mass spectrometry m multiplet; NAC, $N$-acetylcysteine s single. 
(Wang et al., 2017). Early metabolic studies described that 6- and 1 '-hydroxy BBR are two major hydroxylation metabolites of BBR catalyzed by CYP2C9 and CYP3A4, respectively (Kobayashi et al., 2012). Recently, Cho et al. (2017) identified novel GSH conjugates derived from 1',6-dihydroxy BBR in human liver microsomal incubations. They further found that the formation of hepatic GSH conjugates was proportional to the elevation of plasma alanine aminotransferase activity in mice treated with BBR (Yoshida et al., 2017).

The aforementioned metabolic studies of BBR focused on its benzofuran ring. In 2015, Kitagawara and coworkers discovered that BBR which contains a phenolic hydroxyl group could be metabolized to a monodebrominated catechol through ipso-substitution of BBR (Kitagawara et al., 2015). Catechols are susceptible to being oxidized to ortho-quinones, which are known to be capable of adducting biologic macromolecules and finally result in toxicities. GSH conjugation is generally considered as an important pathway to protect against the attack of electrophilic agents. BBR may also be detoxified by reaction with GSH to form GSH conjugates in vivo that are mainly excreted in bile. GSH conjugates are often converted to mercapturic acids through enzymatic hydrolytic cleavage of glutamic acid and glycine followed by $\mathrm{N}$-acetylation of the remaining cysteine conjugates before excretion in urine (Poon et al., 2001; Cosnier et al., 2013). When GSH was depleted, hepatic protein was prone to being exposed to the electrophiles to form protein adduction. These mercapturates and protein adduction derived from the oxidative debromination metabolite of BBR can provide additional insight into its metabolic pathways. This study aimed to investigate and identify the ipso-substitution metabolite of BBR in mice, including the corresponding GSH conjugate in bile, mercapturic acid in urine, as well as protein adduction in liver.

\section{Materials and Methods}

\section{Materials}

BBR $(>98 \%)$ was obtained from Aladdin Industrial Technology Co., Ltd. (Shanghai, China). Dithiothreitol ( $\geq 97 \%), N$-acetylcysteine (NAC; $>97 \%$ ), GSH $(>98 \%), L$-cysteine $(>97 \%)$, and reduced nicotinamide adenine dinucleotide phosphate (NADPH) were purchased from Sigma-Aldrich (St. Louis, MO). Pronase E ( $>98 \%)$ was acquired from Shanghai Yuanye Biological Technology Co., Ltd. (Shanghai, China). All organic solvents were from Fisher Scientific (Springfield, NJ). All reagents used for experiments were of either analytical or high-performance liquid chromatography grade.

\section{Animal Experiments}

Male Kunming mice (22 $\pm 2 \mathrm{~g})$ were supplied by the Animal Center of Shenyang Pharmaceutical University (Shenyang, China). Animals were acclimatized at a temperature- and humidity-controlled facility through 12-hour light/dark cycles and allowed free access to food and water. All procedures were in accordance with the guide for the Ethics Review Committee for Animal Experimentation of Shenyang Pharmaceutical University.

One group of mice $(n=4)$ treated intraperitoneally with vehicle were individually placed in metabolic cages overnight for the collection of blank urine. Then mice were treated (intraperitoneally) with BBR dissolved in corn oil $(25 \mathrm{mg} / \mathrm{ml}, 10 \mathrm{ml} / \mathrm{kg})$ at a dose of $100 \mathrm{mg} / \mathrm{kg}$. Urine samples were collected up to 24 hours after the administration and kept cold on ice. Free access to water was provided during the experiment.

In a separate study, mice were treated (i.p.) with BBR at doses of 50, 100, or $200 \mathrm{mg} / \mathrm{kg}$ ( $n=4$ in each group). The animals were anesthetized, followed by the collection of liver tissues 4 hours after the treatment.

For time-dependent experiments, mouse livers were harvested at $0.17,0.5,1,2$, $4,8,12$, and 24 hours after the administration of BBR (i.p.) at $100 \mathrm{mg} / \mathrm{kg}(n=4$ for each time point). At the time points of 1,2, and 4 hours, gallbladders were also collected for the detection of GSH conjugates. Blank bile collected from vehicletreated mice was included. The collected biologic samples were stored at $-80^{\circ} \mathrm{C}$ until analysis.
Sample Preparation for Liquid Chromatography Coupled to Tandem Mass Spectrometry Analysis

For identification of urinary NAC and biliary GSH conjugates in BBR-treated mice, the collected urine samples ( 24 hours) or bile samples (1,2, and 4 hours) as indicated earlier were pooled. A total of $0.6 \mathrm{ml}$ of urine and $0.15 \mathrm{ml}$ of bile were then subjected to protein precipitation with triple volumes of cold acetonitrile. After centrifuging at 19,000 $\mathrm{g}$ for 10 minutes, the resulting supernatants were concentrated to dryness in a stream of nitrogen at $25^{\circ} \mathrm{C}$. The residues were redissolved in $200 \mu \mathrm{l}$ of $0.2 \%(\mathrm{v} / \mathrm{v})$ acetic acid in water. The pretreated urine or bile samples were loaded onto a ProElut C18 cartridge (500 mg, $50 \mu \mathrm{m}, 60 \AA$ A Dikma, Lake Forest, CA) that had been conditioned with $4.0 \mathrm{ml}$ of methanol and $4.0 \mathrm{ml}$ of $0.2 \%(\mathrm{v} / \mathrm{v})$ acetic acid in water. After a complete passage of the samples, each cartridge was rinsed with $5.0 \mathrm{ml}$ of $0.2 \%(\mathrm{v} / \mathrm{v})$ acetic acid in water, then $5.0 \mathrm{ml}$ of $0.2 \%$ acetic acid in methanol/water $(10 / 90, \mathrm{v} / \mathrm{v})$. Elution was performed by adding $10.0 \mathrm{ml}$ of $0.2 \%$ acetic acid in methanol/water $(90 / 10, \mathrm{v} / \mathrm{v})$. The pooled eluates were concentrated to dryness, and the resulting residues were redissolved in $100 \mu \mathrm{l}$ of $50 \%$ acetonitrile in water. A $10-\mu \mathrm{l}$ aliquot of the supernatants was analyzed by liquid chromatography coupled to tandem mass spectrometry (LC-MS/MS).

For determination of BBR-derived GSH conjugates in mouse liver, liver samples $(0.3 \mathrm{~g})$ were homogenized in $3.0 \mathrm{ml}$ of phosphate buffer $(\mathrm{pH} 7.4)$ followed by centrifuging at $8000 \mathrm{~g}$ for 10 minutes. A 2.0 -ml aliquot of acetonitrile containing internal standard (IS; $50 \mathrm{ng} / \mathrm{ml}$ of propranolol) was added to $1.0 \mathrm{ml}$ of the supernatants. The mixtures were vortex mixed and then centrifuged at $19,000 \mathrm{~g}$ for 10 minutes to precipitate protein. The resulting supernatants were dried by $\mathrm{N}_{2}$ flow and reconstituted in $100 \mu \mathrm{l}$ of $50 \%$ acetonitrile in water for LC-MS/MS analysis.

For assessment of BBR-derived protein adductions in mouse liver, experiments were carried out according to our established method (Wang et al., 2016a). In brief, liver homogenates prepared as described earlier $(1.0 \mathrm{ml})$ were denatured at $60^{\circ} \mathrm{C}$ in a water bath for 30 minutes. The resulting precipitated protein was suspended in $200 \mu \mathrm{l}$ of ammonium bicarbonate solution $(50 \mathrm{mM}$, $\mathrm{pH} 8.0$ ) containing dithiothreitol $(5.0 \mathrm{mM})$, followed by incubation at $60^{\circ} \mathrm{C}$ for 1 hour. Then, a mixture of Pronase E $(2.0 \mathrm{mg} / \mathrm{ml})$, chymotrypsin $(1.0 \mathrm{mg} / \mathrm{ml})$, and $\mathrm{CaCl}_{2}(5.0 \mathrm{mM})$ was added with continuous incubation at $37^{\circ} \mathrm{C}$ for 12 hours. The digestion mixtures were centrifuged, and the resulting supernatants were mixed with $10 \mu \mathrm{l}$ of IS solution ( $50 \mathrm{ng} / \mathrm{ml}$ of propranolol) before LC-MS/MS analysis.

\section{Microsomal Incubations}

Mouse liver microsomes were prepared as we published previously (Lin et al., 2007). Incubation mixtures contained mouse liver microsomes (1.0 mg protein $/ \mathrm{ml}$ ); BBR $(75 \mu \mathrm{M}) ; \mathrm{MgCl}_{2}(3.2 \mathrm{mM})$; and $L$-cysteine, NAC, or GSH $(10 \mathrm{mM})$ in $500 \mu$ l of phosphate buffer ( $\mathrm{pH}$ 7.4). The reaction was commenced by addition of NADPH $(1.0 \mathrm{mM})$ and quenched by addition of equal volume of ice-cold acetonitrile after 60 -minute incubation at $37^{\circ} \mathrm{C}$. Control incubations without $\mathrm{NADPH}$ were included. The incubation mixtures were vortex mixed and then centrifuged at $4^{\circ} \mathrm{C}$ at $19,000 \mathrm{~g}$ for 10 minutes to remove precipitated protein. The resulting supernatants were dried and reconstituted in $100 \mu \mathrm{l}$ of $50 \%$ acetonitrile in water, followed by LC-MS/MS analysis.

\section{Chemical Synthesis}

Mercapturic acid $\mathbf{1 1}$ was synthesized as described in Scheme 1 to facilitate metabolite identification and to define the oxidative debromination pathway of BBR.

2-Acetylbenzofuran (3). 2-Hydroxybenzaldehyde (1, $0.60 \mathrm{~g}, 4.91 \mathrm{mmol})$ was added to a mixture of $\mathrm{KOH}(0.33 \mathrm{~g}, 5.89 \mathrm{mmol})$ in ethanol $(30 \mathrm{ml})$ with stirring. The resulting yellow mixture was refluxed for 30 minutes, followed by dropwise addition of chloroacetone $(2,0.68 \mathrm{~g}, 7.37 \mathrm{mmol})$. The solution was filtered immediately after heating under reflux for 3 hours. The solvent was removed under vacuum to yield an orange wet solid $(0.71 \mathrm{~g}, 90 \%$ yield $) .{ }^{1} \mathrm{H}$ NMR was as follows ( $300 \mathrm{MHz}, \mathrm{CDCl}_{3}$, Supplemental Fig. S4): $\delta 7.70$ (doublet or d, $1 \mathrm{H}$, $J=5.9 \mathrm{~Hz}$, aromatic-H or Ar-H), 7.57 (doublet of doublets, $1 \mathrm{H}, J=0.5,6.3 \mathrm{~Hz}$, $\mathrm{Ar}-\mathrm{H}$ ), 7.47 (multiplet or m, $2 \mathrm{H}, \mathrm{Ar}-\mathrm{H}$ ), $7.31\left(\mathrm{~m}, 1 \mathrm{H}, \mathrm{Ar}-\mathrm{H}\right.$ ), 2.60 (single or s, $3 \mathrm{H}, \mathrm{CH}_{3}$ ). ${ }^{13} \mathrm{C}$ NMR was as follows (150 MHz, $\mathrm{CDCl}_{3}$, Supplemental Fig. S9): 188.62 , $155.65,152.64,128.24,127.03,123.88,123.26,112.99,112.43,26,42$. Mass spectrometry (MS) was as follows [electrospray ionization (ESI)]: $m / z 160.1[\mathrm{M}+\mathrm{H}]^{+}$. 


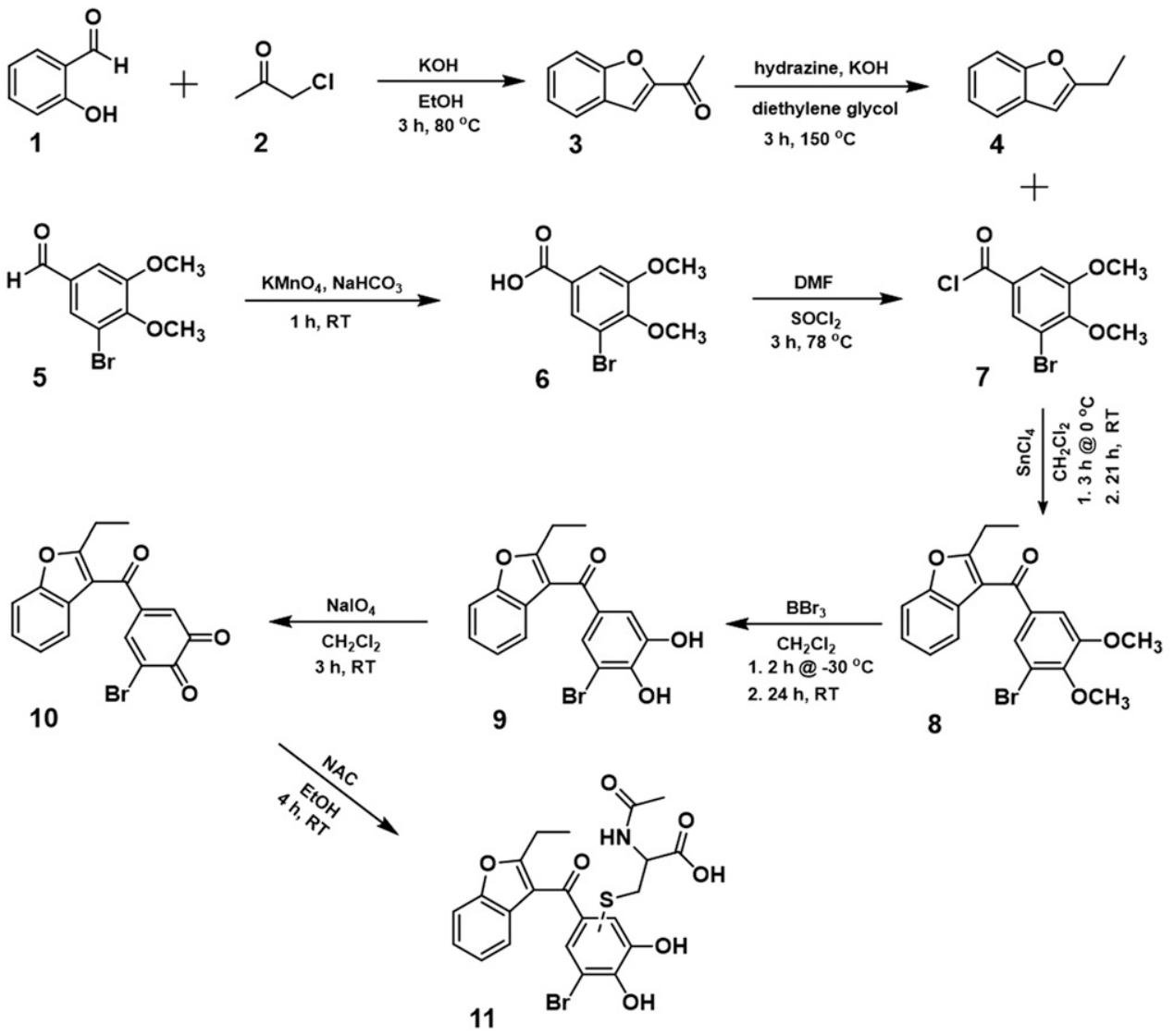

Scheme 1. Synthetic routes of BBR-NAC conjugate (11). DMF, dimethyl formamide; $\mathrm{RT}$, room temperature.

2-Ethylbenzofuran (4). A solution of 2-acetylbenzofuran (3,0.52 g, $3.22 \mathrm{mmol})$ and hydrazine monohydrate $(0.40 \mathrm{~g}, 8.05 \mathrm{mmol})$ suspended in diethylene glycol (50 ml) was mixed, slowly heated to $150^{\circ} \mathrm{C}$, and refluxed for 30 minutes. After cooling to room temperature, $\mathrm{KOH}(0.36 \mathrm{~g}, 6.44 \mathrm{mmol})$ was added, and the resulting mixture was stirred for 3 hours under refluxing. The solution was next diluted with $20 \mathrm{ml}$ of water and extracted with $\mathrm{CH}_{2} \mathrm{Cl}_{2}(20 \mathrm{ml} \times 3)$. The combined organic phase was washed with water and brine, dried with anhydrous sodium sulfate, and evaporated to yield a brown oil $\left(0.4 \mathrm{~g}, 85 \%\right.$ yield). ${ }^{1} \mathrm{H}$ NMR was as follows (300 MHz, $\mathrm{CDCl}_{3}$, Supplemental Fig. S5): $\delta 7.34(\mathrm{~m}, 2 \mathrm{H}, \mathrm{Ar}-\mathrm{H})$, $7.07(\mathrm{~m}, 2 \mathrm{H}, \mathrm{Ar}-\mathrm{H}), 6.24(\mathrm{~d}, 2 \mathrm{H}, J=0.7 \mathrm{~Hz}, \mathrm{Ar}-\mathrm{H}), 2.68\left(\mathrm{~m}, 2 \mathrm{H}, \mathrm{CH}_{2}\right)$, $1.21\left(\mathrm{~m}, 3 \mathrm{H}, \mathrm{CH}_{3}\right) .{ }^{13} \mathrm{C} \mathrm{NMR}$ was as follows $\left(150 \mathrm{MHz}, \mathrm{CDCl}_{3}\right.$, Supplemental Fig. S10): 160.93, 154.65, 129.00, 123.03, 122.33, 120.15, 110.64, 100.95, 21.75, 11.82. MS was as follows (ESI): $m / z 146.1[\mathrm{M}+\mathrm{H}]^{+}$.

3-Bromo-4,5-dimethoxybenzoic Acid (6). 3-Bromo-4,5-dimethoxybenzaldehyde $(5,0.65 \mathrm{~g}, 2.65 \mathrm{mmol})$ was added to a solution of $0.1 \mathrm{M} \mathrm{NaHCO}_{3}(30 \mathrm{ml})$. The resulting suspension was slowly heated to $90^{\circ} \mathrm{C}$. After 10-minute stirring, $\mathrm{KMnO}_{4}$ $(0.42 \mathrm{~g}, 2.65 \mathrm{mmol})$ was added and the mixture was stirred for 1 hour, followed by filtration. The resulting filtrates were washed with $10 \% \mathrm{HCl}$, and white solid $(0.62 \mathrm{~g}$, $90 \%$ yield) was obtained. ${ }^{1} \mathrm{H}$ NMR was as follows $\left(300 \mathrm{MHz}, \mathrm{CDCl}_{3}\right.$, Supplemental Fig. S6): $\delta 9.84$ (broads, 1H, OH), 7.94 (s, 1H, Ar-H), 7.58 (s, 1H, Ar-H), 3.94 (s, 6H, $\left.2 \times \mathrm{OCH}_{3}\right) \cdot{ }^{13} \mathrm{C}$ NMR was as follows ( $150 \mathrm{MHz}, \mathrm{CDCl}_{3}$, Supplemental Fig. S11): $170.51,153.36,151.21,127.47,125.65,117.51,113.11,60.76,56.26$. MS was as follows (ESI): $m / z, 260.9[\mathrm{M}+\mathrm{H}]^{+}(50 \%), 262.9[\mathrm{M}+\mathrm{H}]^{+}(50 \%)$.

3-Bromo-4,5-dimethoxybenzoyl Chloride (7). A catalytic amount of dry dimethyl formamide (one drop) was added to a stirred solution of dried carboxylic acid $6(0.54 \mathrm{~g}, 2.06 \mathrm{mmol})$ in $15 \mathrm{ml}$ of $\mathrm{SOCl}_{2}$. The reaction was allowed to reflux at $78^{\circ} \mathrm{C}$ for 3 hours and was then cooled to room temperature. The excess of $\mathrm{SOCl}_{2}$ was removed in a vacuum to give benzoyl chloride 7 , which was used directly for the following Friedel-Crafts reaction.

2-Ethyl-3-(3-bromo-4,5-dimethoxybenzoyl)-benzofuran (8). Benzoyl chloride 7 dissolved in $\mathrm{CH}_{2} \mathrm{Cl}_{2}$ was added dropwise to a vigorously stirred solution of 2-ethyl-benzofuran $(4,0.25 \mathrm{~g}, 1.72 \mathrm{mmol})$ in $10 \mathrm{ml}$ of $\mathrm{CH}_{2} \mathrm{Cl}_{2}$ which was precooled in an ice-water bath. Next, tin (IV) chloride $(0.54 \mathrm{~g}, 2.06 \mathrm{mmol})$ was carefully added into the mixture. The mixture was stirred for 3 hours and then allowed to stir at room temperature for 21 hours. The reaction mixture was diluted with water and extracted with $\mathrm{CH}_{2} \mathrm{Cl}_{2}$. The pooled organic layer was washed with $\mathrm{HCl}(0.5 \mathrm{~N})$, water, $\mathrm{NaHCO}_{3}$, and brine. The resultant $\mathrm{CH}_{2} \mathrm{Cl}_{2}$ layer was dried with anhydrous sodium sulfate, filtered, evaporated, and purified via silica gel column chromatography to give the yellow oil $(0.2 \mathrm{~g}, 30 \%$ yield $)$. ${ }^{1} \mathrm{H}$ NMR was as follows (300 MHz, $\mathrm{CDCl}_{3}$, Supplemental Fig. S7): $\delta 7.61(\mathrm{~d}, 1 \mathrm{H}$, $J=1.44 \mathrm{~Hz}, \mathrm{Ar}-\mathrm{H}), 7.46(\mathrm{~m}, 2 \mathrm{H}, \mathrm{Ar}-\mathrm{H}), 7.39(\mathrm{~d}, 1 \mathrm{H}, J=1.41 \mathrm{~Hz}, \mathrm{Ar}-\mathrm{H})$, $7.29(\mathrm{~m}, 1 \mathrm{H}, \mathrm{Ar}-\mathrm{H}), 7.23(\mathrm{~m}, 1 \mathrm{H}, \mathrm{Ar}-\mathrm{H}), 3.94\left(\mathrm{~s}, 3 \mathrm{H}, \mathrm{OCH}_{3}\right), 3.87\left(\mathrm{~s}, 3 \mathrm{H}, \mathrm{OCH}_{3}\right)$, 2.89 (quartet, $2 \mathrm{H}, J=5.67 \mathrm{~Hz}, \mathrm{CH}_{2}$ ), 1.34 (triplet, $3 \mathrm{H}, J=5.64 \mathrm{~Hz}, \mathrm{CH}_{3}$ ). ${ }^{13} \mathrm{C}$ NMR was as follows $\left(150 \mathrm{MHz}, \mathrm{CDCl}_{3}\right.$, Supplemental Fig. S12): $189.40,166.29,153.62,153.59,150.28,135.62,126.71,126.67,124.48$, $123.59,121.14,117.28,115.61,111.91,111.00,60.74,56.19,21.91,12.22 . \mathrm{MS}$ was as follows (ESI): $m / z 389.0[\mathrm{M}+\mathrm{H}]^{+}(50 \%), 391.0[\mathrm{M}+\mathrm{H}]^{+}(50 \%)$.

2-Ethyl-3-(3-bromo-4,5-dihydroxybenzoyl)-benzofuran (9). To a solution of 2-ethyl-3-(3-bromo-4,5-dimethoxybenzoyl)-benzofuran (8, 0.16 g, $0.41 \mathrm{mmol}$ ) in $\mathrm{CH}_{2} \mathrm{Cl}_{2}(10 \mathrm{ml})$ under a nitrogen atmosphere, precooled at $-30^{\circ} \mathrm{C}, 1 \mathrm{M}$ $\mathrm{BBr}_{3} / \mathrm{CH}_{2} \mathrm{Cl}_{2}(1.64 \mathrm{ml}, 1.64 \mathrm{mmol})$ was added. The mixture was stirred at $-30^{\circ} \mathrm{C}$ for 2 hours, and then stirred at room temperature for 24 hours. The reaction was quenched by addition of cold water $(10 \mathrm{ml})$ and then extracted with $\mathrm{CH}_{2} \mathrm{Cl}_{2}$. The pooled organic layer was washed with water and brine, dried with anhydrous sodium sulfate, and concentrated. The product was purified by silica gel column chromatography to give a brown solid ( $0.12 \mathrm{~g}, 82 \%$ yield). ${ }^{1} \mathrm{H}$ NMR was as follows (300 MHz, $\mathrm{CDCl}_{3}$, Supplemental Fig. S8): $\delta 10.45$ (broads, $2 \mathrm{H}$, $\mathrm{OH}), 7.77(\mathrm{~d}, 1 \mathrm{H}, J=8.15 \mathrm{~Hz}, \mathrm{Ar}-\mathrm{H}), 7.51(\mathrm{~m}, 5 \mathrm{H}, \mathrm{Ar}-\mathrm{H}), 2.95$ (quartet, $2 \mathrm{H}, J=7.70 \mathrm{~Hz}, \mathrm{CH}_{2}$ ), 1.40 (triplet, $3 \mathrm{H}, J=7.44 \mathrm{~Hz}, \mathrm{CH}_{3}$ ). ${ }^{13} \mathrm{C}$ NMR was as follows (150 MHz, $\mathrm{CDCl}_{3}$, Supplemental Fig. S13): 186.36, 162.46, 151.07, $146.08,144.07,128.46,124.66,123.06,122.65,121.75,118.80,113.47,112.69$, $109.17,107.26,22.53,11.97$. MS was as follows (ESI): $\mathrm{m} / \mathrm{z} 361.0[\mathrm{M}+\mathrm{H}]^{+}(50 \%)$, $363.0[\mathrm{M}+\mathrm{H}]^{+}(50 \%)$.

\section{Mercapturic Acid 11}

To a stirred solution of compound $9(0.1 \mathrm{~g}, 0.28 \mathrm{mmol})$ dissolved in $10 \mathrm{ml}$ of $\mathrm{CH}_{2} \mathrm{Cl}_{2}, 10 \mathrm{ml}$ of $\mathrm{NaIO}_{4}(1.2 \mathrm{~g}, 5.6 \mathrm{mmol})$ in water was added over 2 minutes, and 

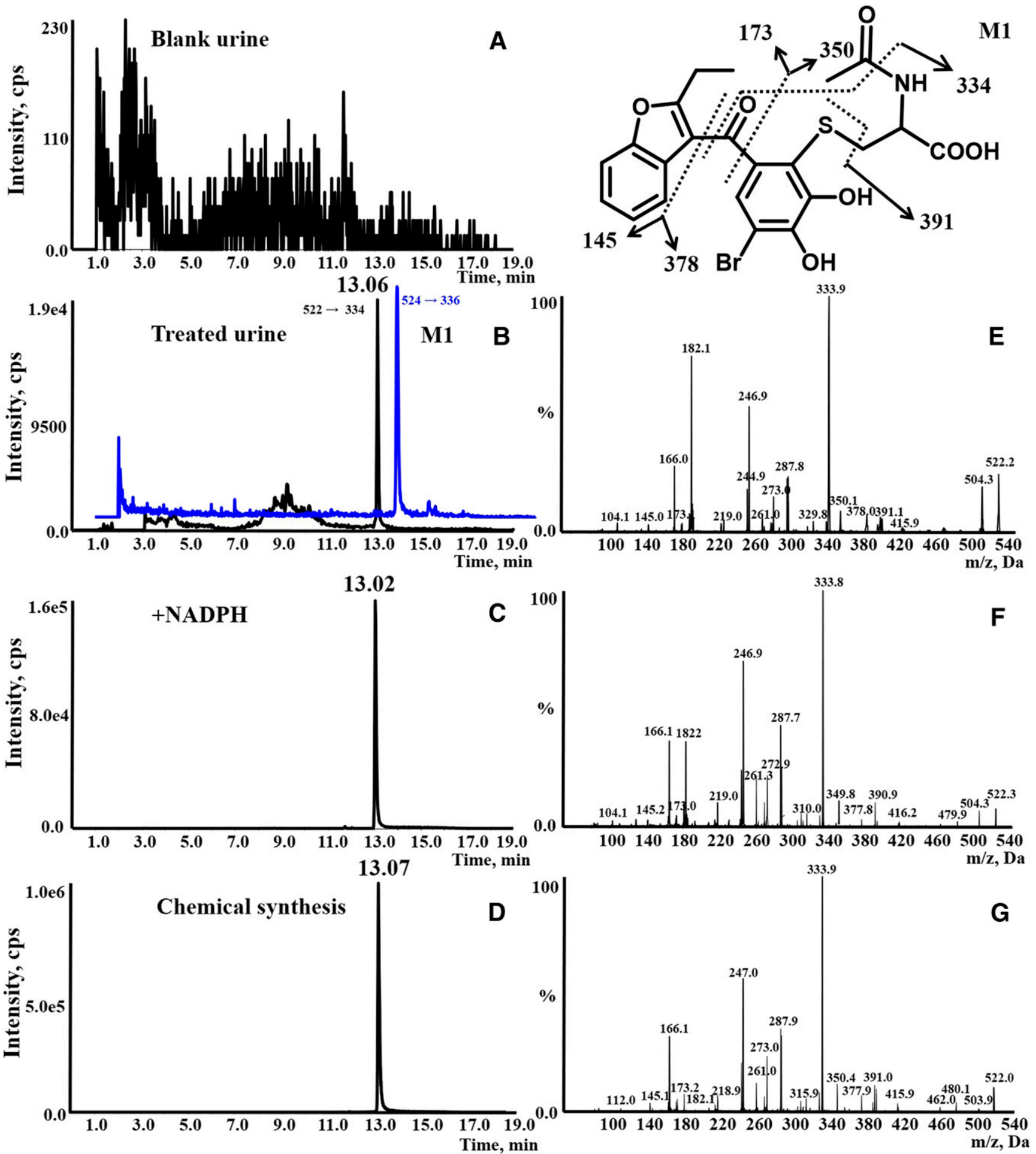

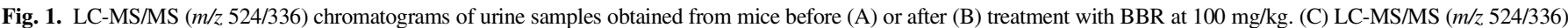

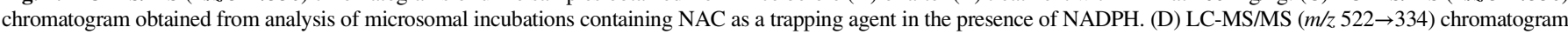

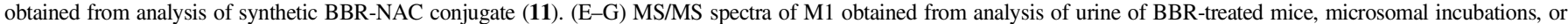
chemical synthesis.

the resulting biphasic mixture was stirred vigorously at room temperature. After 3 hours, compound 9 was completely vanished as monitored by thin layer chromatography. The biphasic mixture was separated, and the organic phase was washed with water and concentrated in vacuo to afford the crude benzoquinone product as a dark red solid. The solution of the benzoquinone in ethanol $(10 \mathrm{ml})$ was added dropwise into a stirred solution of NAC $(0.09 \mathrm{~g}$, $0.56 \mathrm{mmol}$ ) in $4 \mathrm{ml}$ of water. After 4 hours, the reaction mixture was concentrated in vacuum to remove ethanol, then extracted with $\mathrm{CH}_{2} \mathrm{Cl}_{2}$. The remaining $\mathrm{CH}_{2} \mathrm{Cl}_{2}$ layer was washed with water and brine, dried with anhydrous sodium sulfate, and concentrated, and the crude product was submitted to semipreparative high-performance liquid chromatography for purification of target compound 11. Unfortunately, the poor yield of compound 11 only allowed us to characterize it by mass spectrometry, as shown in the Results section. 

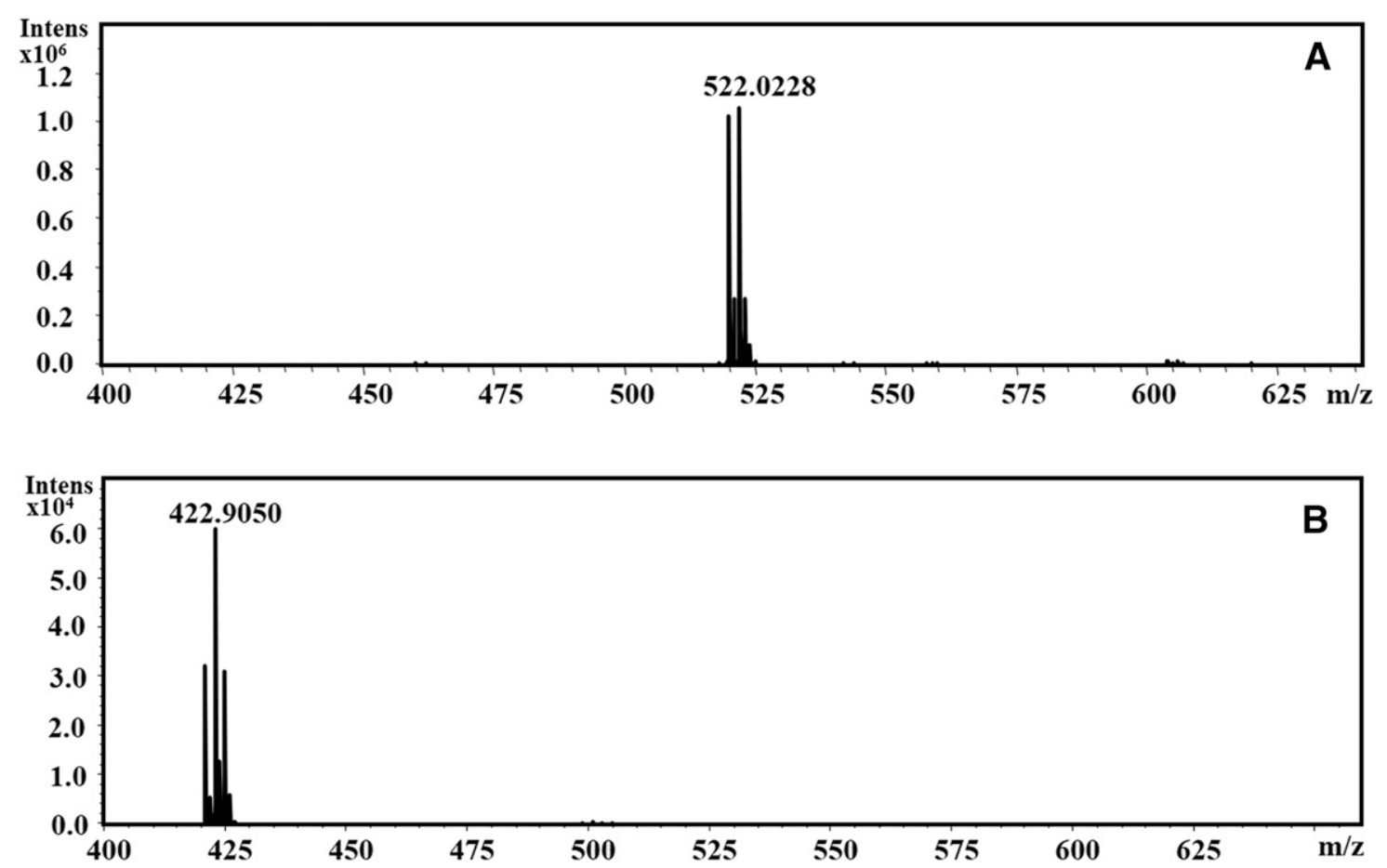

Fig. 2. High-resolution mass spectrum of synthetic BBR-NAC conjugate [11 (A)] and BBR standard (B) analyzed by microQ-TOF MS (Bruker Corporation).

\section{LC-MS/MS Method}

Sample analyses were carried out using a SCIEX Instrument 5500 triple quadrupole mass spectrometry (Applied Biosystems, Foster City, CA) connected to an Agilent 1260 Series Rapid Resolution LC system (Agilent Technologies, Santa Clara, CA). MS analyses were performed in electrospray positive ionization mode by multiple reaction monitoring (MRM) scanning. The MRM transitions (declustering potential, collision energy, collision cell exit potential), $m / z 522 \rightarrow 334(25,110,10), m / z 666 \rightarrow 391(30,110,10)$, $m / z \quad 480 \rightarrow 334(25,110,10)$, and $m / z \quad 260.3 \rightarrow 116.3(25,75,20)$, were monitored for NAC conjugate (Fig. 1), GSH conjugate (Figs. 3 and 4), cysteine adduct (Figs. 5-7), and propranolol (IS), respectively. The optimized MS conditions were as follows: ion spray voltage (IS), $5500 \mathrm{~V}$; ion source temperature, $600^{\circ} \mathrm{C}$; curtain gas, $35 \mathrm{psi}$; gas 1 (GS1), $50 \mathrm{psi}$; GS2, 60 psi.

In addition, a SCIEX Instrument 4000 Q-Trap (Applied Biosystems) equipped with an Agilent 1260 Series Rapid Resolution LC system was applied to obtain the MS/MS spectra (Figs. 1,3, and 5). The information-dependent acquisition method was used to trigger the enhanced product ion in positive mode by MRM scanning. The collision energy value was set at $40 \mathrm{eV}$ with a spread of $5 \mathrm{eV}$. Other parameters were the same as described earlier except for GS2 (50 psi) and curtain gas (25 psi). The MS data were analyzed by Applied Biosystems/SCIEX Analyst 1.6.2 software.

Mass spectrometry analysis was also performed on a hybrid quadrupole timeof-flight MS system (microQ-TOF; Bruker Corporation, Billerica, MA) to further characterize compound $\mathbf{1 1}$ (Fig. 2; Table 1). The ESI source was set in negative mode with the following parameters: capillary voltage, 24,500 V; endplate offset, $2500 \mathrm{~V}$; dry gas, high-purity nitrogen $\left(\mathrm{N}_{2}\right)$; dry gas flow rate, 4.01 per minute; gas temperature, $180^{\circ} \mathrm{C}$, and nebulizer gas pressure, 0.3 bar. The data were analyzed by Bruker Daltonics Data Analyst 3.4 software.
Analytical separations of NAC conjugate, GSH conjugate, and cysteine adduct were achieved on an Agilent Poroshell $120 \mathrm{XB}^{-\mathrm{C}_{18}}$ column $(4.6 \times 100 \mathrm{~mm}$, $2.7 \mu \mathrm{m}$; Agilent Technologies) at a flow rate of $0.5 \mathrm{ml} / \mathrm{min}$. The mobile phases were composed of $0.1 \%$ formic acid in water (A) and $0.1 \%$ formic acid in acetonitrile (B). Ten microliters of sample was injected and separated as follows: $10 \%$ B for 2 minutes, 10\%-100\% B linear gradient for 12 minutes, a wash at $100 \%$ B for 2 minutes, $100 \%-10 \%$ B linear gradient for 1 minutes, and re-equilibration at $10 \% \mathrm{~B}$ for 2 minutes (total run time, 19 minutes). For semipreparative separation of the synthetic NAC conjugate 11, a YMC-Pack ODS-A column $(10 \times 250 \mathrm{~mm}, \mathrm{~S}-5,12 \mathrm{~nm}$; YMC Co., Ltd. $)$ was applied at a flow rate of $3 \mathrm{ml} / \mathrm{min}$. Separation was accomplished by isocratic elution with $30 \%$ B for 50 minutes as indicated earlier.

\section{Statistical Analysis}

Statistical analyses were performed by unpaired Student's $t$ test using GraphPad Prism 5.0 software (GraphPad Software). Statistical significance was defined as $P<0.05,0.01$, or 0.001 .

\section{Results}

Urinary NAC Conjugate Derived from Oxidative Debromination of BBR in Mice. We proposed that oxidative debromination of BBR in vivo produces $o$-quinone metabolite $\mathbf{1 0}$ (Scheme 2). The metabolic activation of BBR was first investigated by monitoring urinary excretion of BBR metabolites in mice, using a designed MRM template as described in the LC-MS/MS Method section. A metabolite (M1) with retention time at 13.02 minutes (Fig. 1B) was

TABLE 1

Summary of mass spectrometric data obtained from microQ-TOF MS analysis of synthetic BBR-NAC conjugate (11) and BBR standard

\begin{tabular}{lccccc}
\hline Description & Formula & Calculated Mass & Measured Mass & Absolute Error & Relative Error \\
\hline & & & {$[M-H]^{-}$} & & $m D a$ \\
M1 & $\mathrm{C}_{22} \mathrm{H}_{19} \mathrm{BrNO}_{7} \mathrm{~S}$ & $520.0071 / 522.0228$ & & $520.0060 / 522.0211$ & $1.13 / 1.71$ \\
BBR & $\mathrm{C}_{17} \mathrm{H}_{11} \mathrm{Br}_{2} \mathrm{O}_{3}$ & $420.9067 / 422.9049 / 424.9032$ & $420.9047 / 422.9050 / 424.9014$ & $2.01 / 0.13 / 1.84$ & $4.78 / 0.31 / 4.33$
\end{tabular}



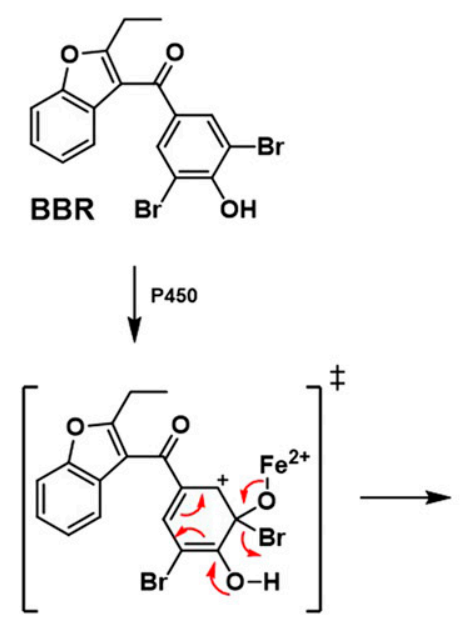

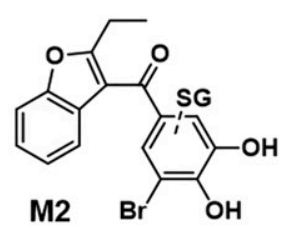

M2
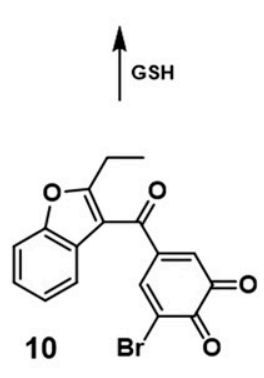

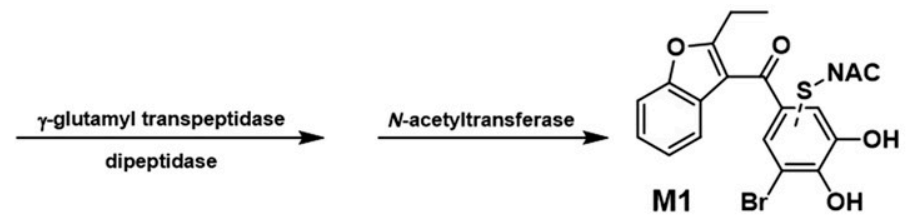

M1

$\mathrm{Br}^{\prime}$

Scheme 2. Proposed pathways of mercapturic acid and protein adduct formation as a result of ipso-substitution of BBR in vivo. P450, cytochrome P450.

observed in urine samples extracted with solid phase extraction. No such metabolite was observed in blank urine (Fig. 1A).

As shown in Fig. 1D, M1 had its protonated molecular ions at $\mathrm{m} / \mathrm{z} 522(50 \%)$ and $524(50 \%)$, signaling that the metabolite was derived from the loss of a bromine atom from BBR. The MS/MS spectrum of M1 provided fragment ions at $\mathrm{m} / \mathrm{z}, 334$ (indicative characteristic fragmentation associated with the cleavage of the NAC moiety) and $\mathrm{m} / \mathrm{z} 391$ (a fragment resulting from the cleavage of the $\mathrm{C}-\mathrm{S}$ bond within NAC), suggesting that NAC participated in the formation of M1. The fragment ions at $m / z, 145$ and 173 (loss of $\mathrm{C}_{10} \mathrm{H}_{9} \mathrm{O}$ and $\mathrm{C}_{11} \mathrm{H}_{9} \mathrm{O}_{2}$ ) were found to be the same as the spectrometric pattern of parent BBR (Wang et al., 2016b), suggesting that the benzofuran ring remained unchanged. This led us to propose that $\mathrm{M} 1$ was derived from quinone metabolite $\mathbf{1 0}$ (a debromination metabolite of BBR) with NAC attaching to the brominated benzoyl ring. Additionally, M1 was observed in NAC-fortified microsomal incubations of BBR (Fig. 1C), which shared the same mass spectrometric pattern (Fig. 1E) as that detected in the urine of BBR-treated mice (Fig. 1D).

LC-MS/MS Analysis of Synthetic BBR-NAC Conjugate (M1). To verify the structure of M1, we chemically synthesized NAC conjugate $\mathbf{1 1}$ by oxidation of compound $\mathbf{9}$ to quinone $\mathbf{1 0}$, followed by reaction with NAC (Scheme 1). The synthetic NAC conjugate showed the same chromatographic behavior (Fig. 1D) and mass spectral identities (Fig. 1G) as those of the metabolite excreted in mouse urine (Fig. 1, B and E). The product was further analyzed by high-resolution electrospray ionization mass spectrometry in negative mode (Fig. 2). The final product clearly possessed the bromine isotope pattern with a molecular cluster of $\mathrm{m} / \mathrm{z} 520.0060$ (50\%) and $522.0211(50 \%)$, and the relative errors between the observed and calculated mass were within $5 \mathrm{ppm}$ (Table 1). Identification of the NAC conjugate provided important evidence for the oxidative debromination pathway of BBR in mice.

GSH Conjugate Derived from Oxidative Debromination of BBR in Mice. In vivo ipso-substitution (oxidative debromination; Scheme 2) metabolism of BBR was also investigated by monitoring the GSH conjugate of $\mathrm{BBR}$ in the bile of mice. After intraperitoneal injection of BBR in mice, one glutathione conjugate-namely, M2-was detected in bile samples. The corresponding LC-MS/MS chromatogram is shown in Fig. 3B. No such metabolite was found in blank bile (Fig. 3A). The observed molecular ion value of M2 was consistent with the calculated $\mathrm{m} / \mathrm{z}$ value of a GSH conjugate derived from quinone metabolite $\mathbf{1 0}$ (oxidative debromination metabolite; Scheme 2). As shown in Fig. 3D, the MS/MS spectrum of M2 showed two characteristic fragment ions, including $\mathrm{m} / \mathrm{z}, 591$ (loss of $75 \mathrm{Da}$, glycinyl portion) and 537 (loss of $129 \mathrm{Da}$, glutamyl portion), indicating that GSH participated in the formation of M2. Product ion $\mathrm{m} / \mathrm{z} 519$ originated from the loss of $129 \mathrm{Da}$ and an $\mathrm{H}_{2} \mathrm{O}$. The ions at $\mathrm{m} / \mathrm{z}, 391$ and 247 were considered to be the indicative fragmentations of BBR moiety, along with the cleavage of the GSH moiety. The fragment ion at $\mathrm{m} / z, 173$ corresponded to the benzofuran ring of BBR, which suggests that the addition of GSH took place on the monobrominated benzoyl ring. As expected, M2 was observed in GSH-supplemented mouse liver microsomal incubations of BBR (Fig. 3C), which showed the same mass spectrometric pattern (Fig. 3E) as the metabolite obtained in mouse bile (Fig. 3D). The GSH conjugate detected in vivo further indicates the proposed oxidative debromination of BBR (Scheme 2).

GSH conjugate derived from metabolite $\mathbf{1 0}$ of BBR was also determined in the livers of mice to ensure the proposed oxidative debromination pathway. As expected, one peak with the same retention time as M2 (found in microsomal incubations; Fig. 3C) was detected by LC-MS/MS using the designed MRM template (data not shown). Additionally, the time course of GSH conjugate was determined in the livers of mice treated with BBR. The GSH conjugate reached its peak 2 hours after administration (Fig. 4).

Protein Adduction by Oxidative Debromination of BBR in Mice. Protein modification derived from the debromination metabolite of BBR was examined in mice by monitoring the corresponding protein adduction that occurs at cysteine residues. One product $\left(\mathrm{M}^{\prime} 3\right)$ with an elution time of 11.40 minutes was detected in the liver homogenate after proteolytic digestion (Fig. 5B). No such product was observed in the digested samples obtained from mice treated with vehicle (Fig. 5A).

The mass spectrum of $\mathrm{M}^{\prime} 3$ displayed its protonated molecular ion at $\mathrm{m} / \mathrm{z}, 480$ (Fig. 5D), which was equal to the calculated $\mathrm{m} / \mathrm{z}$ value of a cysteine conjugate derived from oxidative debromination metabolite 10 (Scheme 2). M'3 exhibited its major product ion at $m / z, 334$, which was formed by the fracture of the benzoyl moiety of BBR containing an intact cysteine. Ion $\mathrm{m} / \mathrm{z} 391$ was assigned to be the fragment resulting from the break of the C-S bond within the cysteine moiety. Product ions at $m / z 247$ and 219 were yielded by the cleavages of the benzoyl moiety of BBR, along with the break of the C-S bond within the cysteine moiety. Ion $m / z, 173$, which corresponds to the benzofuran ring of BBR, was also observed in the mass spectrum of $\mathrm{M}^{\prime} 3$. The MS/MS pattern led us to surmise that the formation of $\mathrm{M}^{\prime} 3$ results from a cysteine conjugate with quinone metabolite 10. Cysteine- and BBR-fortified microsomal incubations were performed to characterize the structure 

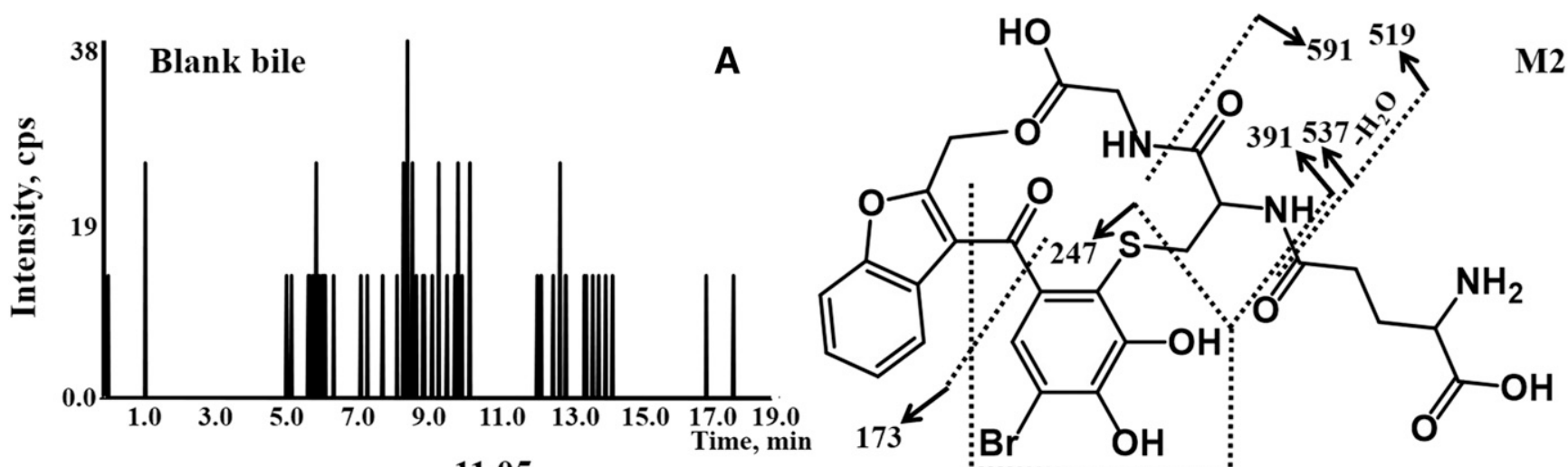

M2
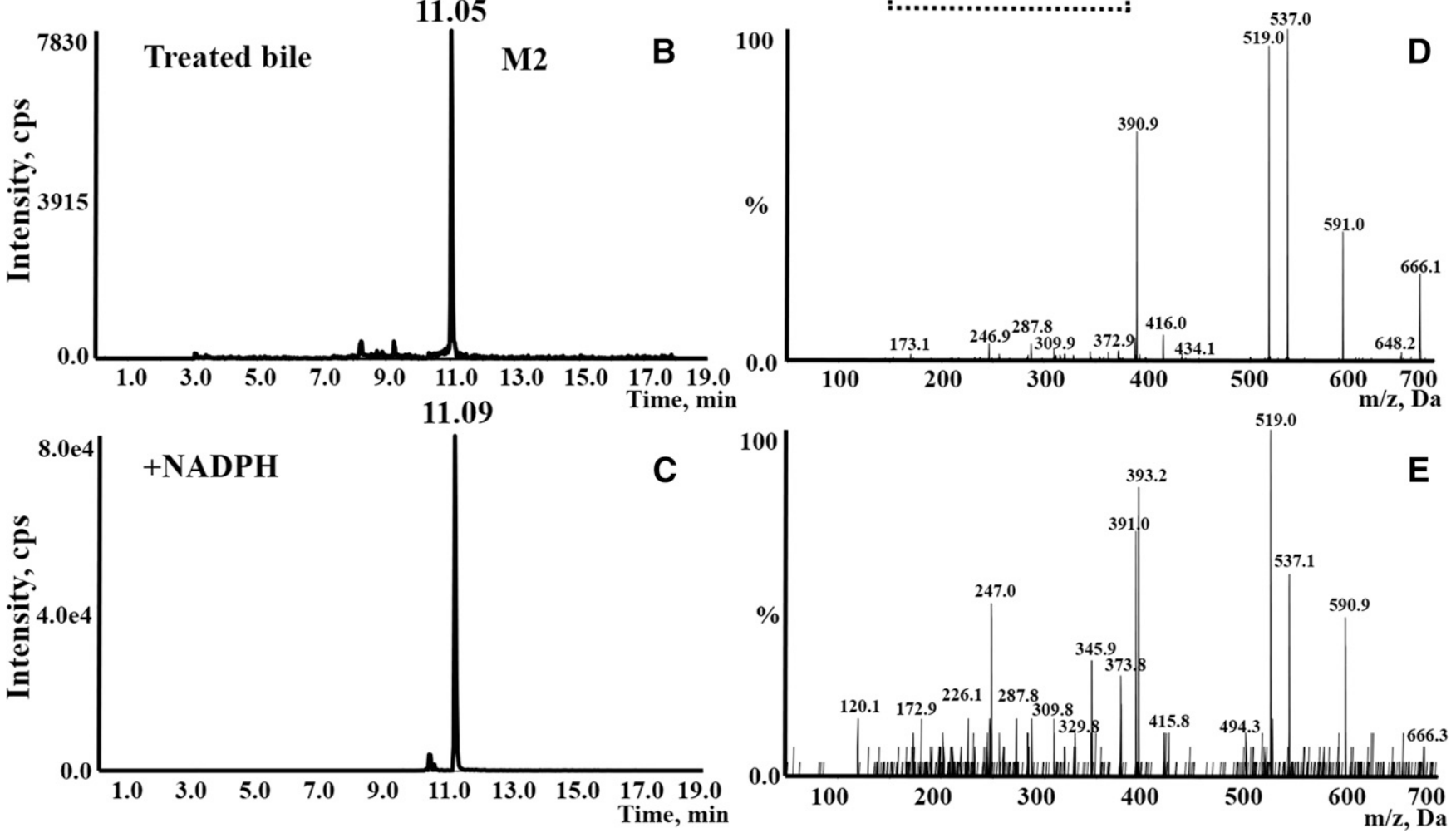

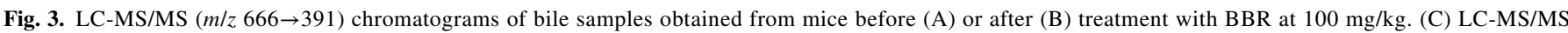

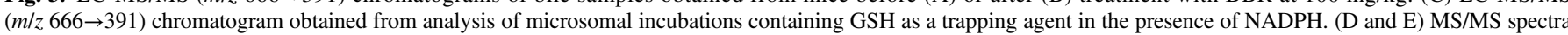
of M2 obtained from analysis of bile samples of BBR-treated mice or microsomal incubations.

of $\mathrm{M}^{\prime} 3$. The cysteine conjugate formed in the incubations shared the same chromatographic (Fig. 5C) and mass spectrometric identities (Fig. 5E) as the product generated in the protein digestion.

Furthermore, we examined the time course of hepatic protein adduction in BBR-treated mice over 24 hours. The protein adduction arising from the debromination metabolite of BBR (10; Scheme 2) reached its peak 4 hours after the administration (Fig. 6). In addition, dose-dependent hepatic protein adduction was monitored in mice 4 hours after BBR treatment $(50,100$, or $200 \mathrm{mg} / \mathrm{kg})$. The observed protein adduction increased with the elevation of the dose of BBR given in mice (Fig. 7).

\section{Discussion}

The hepatotoxicity of BBR has been well documented, and cytochrome $\mathrm{P} 450$-mediated metabolic activation has been suggested to be involved in BBR-induced liver injuries. The present study focused on the investigation of the oxidative debromination pathway of $\mathrm{BBR}$ in vivo, along with protein modification derived from the resulting reactive metabolite.
GSH conjugation is considered to be a common detoxification process during the metabolism of xenobiotics. GSH conjugates undergo a further process and are often converted to mercapturic acids

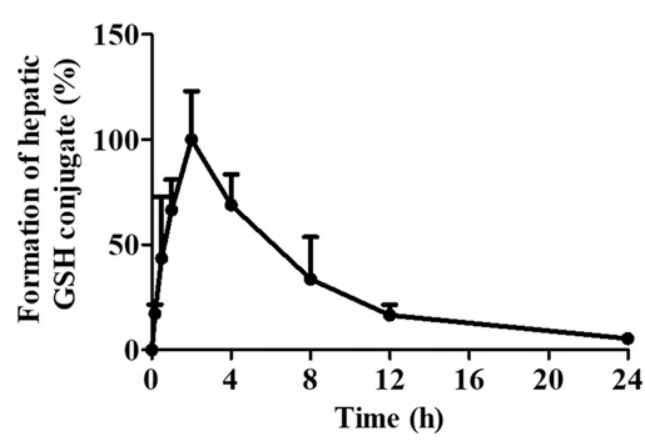

Fig. 4. Time-course changes in GSH conjugate. Mice were treated (i.p.) with BBR at $100 \mathrm{mg} / \mathrm{kg}$. GSH conjugate was examined at various time points after administration $(n=4)$. The most abundant GSH conjugate detected in mouse liver tissues was normalized to $100 \%$. 

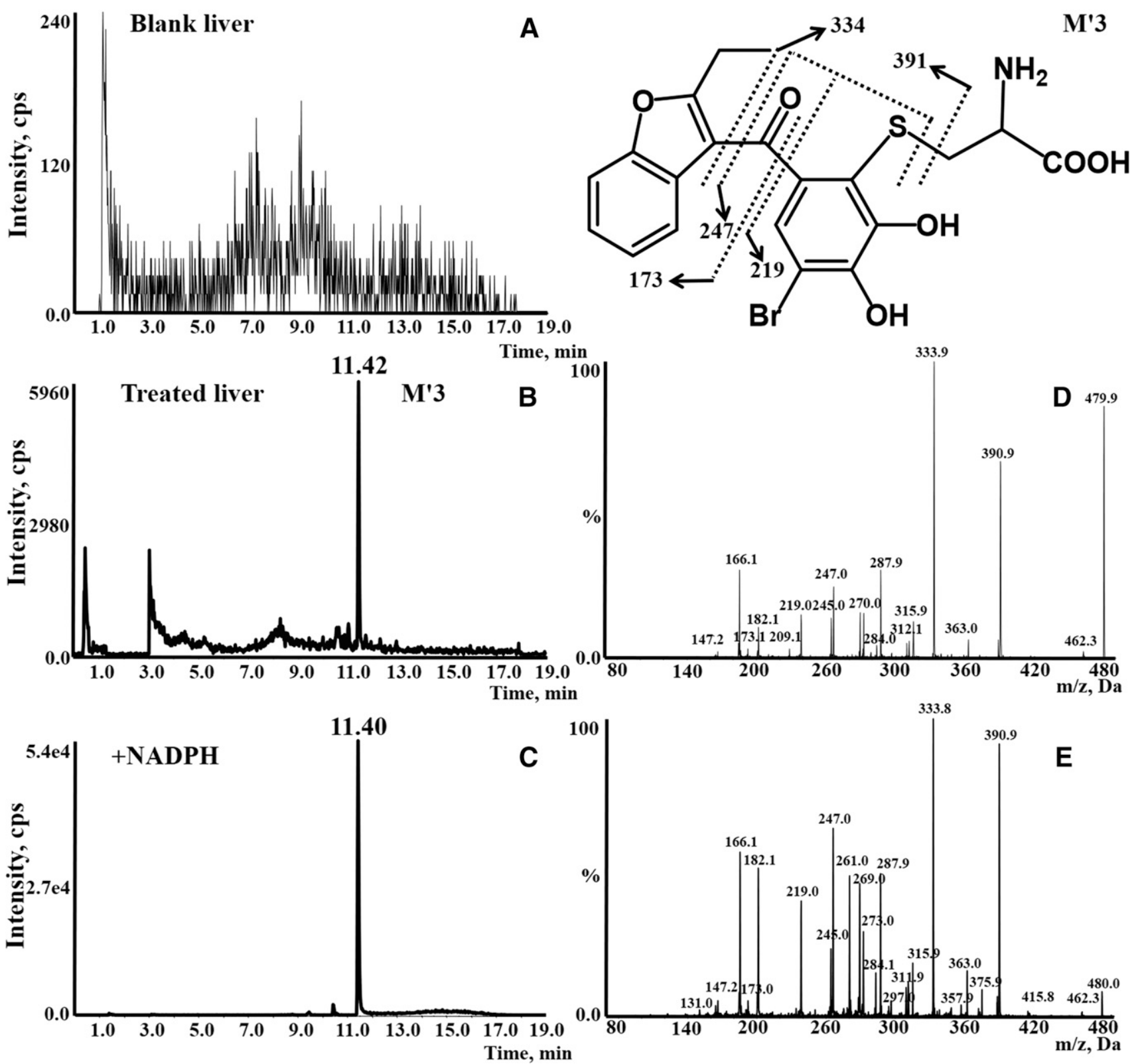

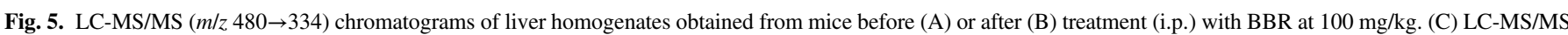

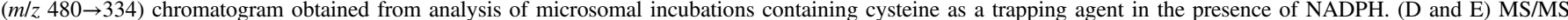
spectra of $\mathrm{M}^{\prime} 3$ obtained from analysis of liver homogenates of BBR-treated mice or microsomal incubations after proteolytic digestion.

(NAC conjugates), which are generally considered as biomarkers of exposure to electrophiles (Poon et al., 2001; Cosnier et al., 2013). In vivo studies were initiated from the detection of urinary mercapturic acids and biliary GSH conjugates in mice. One NAC conjugate (M1; Fig. 1B) and one GSH conjugate (M2; Fig. 3B) were detected in the urine and bile samples of BBR-treated mice, respectively. In addition, these conjugates were also found in microsomal incubations supplemented with NAC or GSH as a trapping agent in an NADPH-dependent manner, and they elicited the same chromatographic and mass spectral identities as those found in biologic samples. The product ion spectra showed that M1 and M2 arose from oxidative debromination of BBR, resulting in the formation of a reactive quinone species, which subsequently reacted with NAC or GSH. The chemical synthesis of the NAC conjugate further allowed us to identify M1. Although there has been difficulty obtaining a sufficient amount of pure NAC conjugate (11; Scheme 1) for NMR characterization, owing to the poor yield of the synthesis and messy impurities of the final crude mixture, LC-MS/MS analysis (Fig. 1, D and G) as well as high-resolution electrospray ionization mass spectrometry (Fig. 2; Table 1) data provided strong evidence for the identity of M1. Two GSH conjugates or NAC conjugates (Supplemental Fig. S3) derived from quinone metabolite $\mathbf{1 0}$ were expected to be formed, but only one conjugate (M1 or M2) was detected in both in vitro and in vivo studies. The failure to form the second conjugate was proposed to be related to the steric hindrance of the ethyl side chain.

Hepatic protein modification by electrophilically reactive metabolites is thought to be an important mechanism for the observed toxicities of many xenobiotics (Boysen and Hecht, 2003; Moghe et al., 2015; Yang and Bartlett, 2016). One protein adduct ( $\mathrm{M}^{\prime} 3$ ) derived from oxidative debromination of BBR was observed in BBR-treated mice (Fig. 5B). And such adduction occurred in a dose- and time-dependent manner (Figs. 6 and 7). The dosage used in this study was based on our previous 


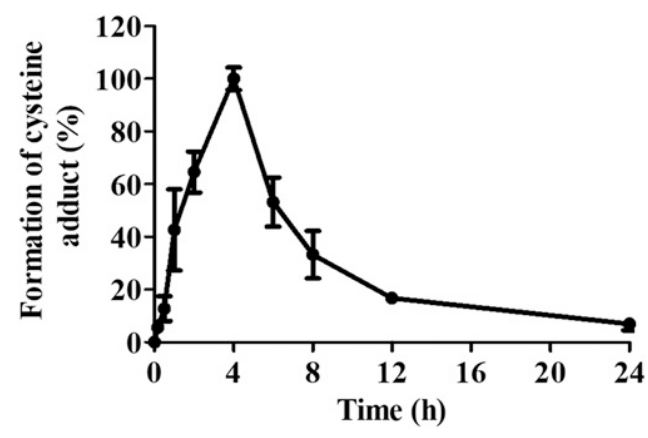

Fig. 6. Time-course changes in protein adduction that occurs at cysteine residues. Mice were treated (i.p.) with BBR at $100 \mathrm{mg} / \mathrm{kg}$. Protein adduction was examined at various time points after administration $(n=4)$. The most abundant protein adduction detected in mouse liver tissues was normalized to $100 \%$.

study (Wang et al., 2016a) in which 30, 50, and $100 \mathrm{mg} / \mathrm{kg}$ were applied for the detection of protein adduction derived from the epoxide metabolite of BBR. In the present study, we increased the dosage to 50, 100, and $200 \mathrm{mg} / \mathrm{kg}$, due to the limited sensitivity of mass spectrometry to detect low levels of protein adducts derived from ipso-substitution of BBR. The protein adduction reached its peak at 4 hours after the administration, which was 2 hours later than the peak time for the formation of the GSH conjugate (Fig. 4). This perhaps results from the readiness of the electrophilic species to access to the sulfhydryl group of abundant GSH, while thiol groups of protein may not be that accessible. In an attempt to compare the time courses of the metabolites of BBR through ipso-substitution and epoxidation pathways, which we published recently (Wang et al., 2016a,b), the formation of epoxidederived GSH conjugate and protein adduction were also monitored in BBR-treated mice at various time points. The formation of epoxidederived GSH conjugate reached its peak (30 minutes) much faster than did the oxidative debrominated metabolite ( 2 hours) (Supplemental Fig. S1). Similarly, the epoxide-derived protein adduction reached its peak 3.5 hours earlier than the binding resulting from metabolite $\mathbf{1 0}$ (Supplemental Fig. S2). This indicates that BBR was more liable to be transformed into an epoxide intermediate in vivo than the oxidative debrominated metabolite.

BBR was reported to undergo an ipso-substitution pathway to form the corresponding benzoquinone, which elicited high cytotoxicity in HepG2 compared with BBR (Kitagawara et al., 2015). At the beginning, we failed to detect the corresponding mercapturic acids and protein adduction that takes place at cysteine residues in BBR-treated mice. We then decided to remove salts from the bile and urine samples by solid phase extraction. As expected, M1 and M2, represented as adducts derived from reaction of NAC or GSH with quinone intermediate 10, were detected after a careful solid phase extraction. The observed protein modification resulting from quinone metabolite $\mathbf{1 0}$ was low in comparison with the protein covalent binding derived from the epoxide metabolite detected in our early work (Wang et al., 2016a). The protein modification (M'3) was not detected until 5 times more liver homogenates were used than for the detection of protein adduction derived from the epoxide. However, we cannot exclude the potential for the toxicity resulting from the reactive intermediate generated via the ipso-substitution mechanism, although the formation of such intermediate is not as much as that of the epoxide intermediate. Quinones are Michael acceptors that are highly electrophilically reactive and covalently bind to nucleophilic centers of proteins and/or DNA. Moreover, quinones are redox active molecules that could generate reactive oxygen species, causing severe oxidative stress within cells (Kim and Lee, 1997). There is considerable

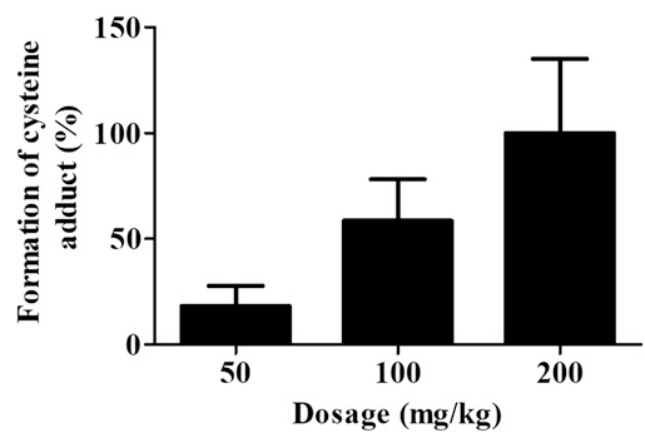

Fig. 7. Dose dependency of protein adduction that takes place at cysteine residues. Mice were treated (i.p.) with BBR at 50, 100, and $200 \mathrm{mg} / \mathrm{kg}$. Protein adduction was examined 4 hours after administration $(n=4)$.

evidence that quinones are linked to a variety of adverse events, including acute cytotoxicity, hepatotoxicity, and carcinogenesis (Bolton et al., 2000; Hughes and Swamidass, 2017).

In this study, we investigated the oxidative debromination pathway of BBR in vivo (Scheme 2). BBR was metabolized to a quinone intermediate, which reacted with GSH. The GSH conjugate underwent sequential hydrolysis and acetylation to a mercapturic acid and was excreted in urine. Protein adduction that happens at cysteine residues was detected in BBR-treated mice after proteolysis of liver homogenates with proteinase. The in vivo studies allowed us to better understand the metabolic activation of BBR, and facilitate the further investigation of the mechanisms of BBR-induced hepatotoxicity.

\section{Authorship Contributions}

Participated in research design: Zheng, Peng.

Conducted experiments: H. Wang, W. Wang, Gong, Z. Wang.

Contributed new reagents or analytic tools: Zhang, S. Wang.

Performed data analysis: H. Wang, Feng.

Wrote or contributed to the writing of the manuscript: $\mathrm{H}$. Wang, Zheng.

\section{References}

Arai M, Yokosuka O, Fujiwara K, Kojima H, Kanda T, Hirasawa H, and Saisho H (2002) Fulminant hepatic failure associated with benzbromarone treatment: a case report. J Gastroenterol Hepatol 17:625-626.

Bolton JL, Trush MA, Penning TM, Dryhurst G, and Monks TJ (2000) Role of quinones in toxicology. Chem Res Toxicol 13:135-160.

Boysen G and Hecht SS (2003) Analysis of DNA and protein adducts of benzo[a]pyrene in human tissues using structure-specific methods. Mutat Res 543:17-30.

Chen M, Bisgin H, Tong L, Hong H, Fang H, Borlak J, and Tong W (2014) Toward predictive models for drug-induced liver injury in humans: are we there yet? Biomarkers Med 8:201-213.

Cho N, Kobayashi K, Yoshida M, Kogure N, Takayama H, and Chiba K (2017) Identification of novel glutathione adducts of benzbromarone in human liver microsomes. Drug Metab Pharmacokinet 32:46-52.

Cosnier F, Cossec B, Burgart M, Nunge H, Brochard C, Décret MJ, and Rémy A (2013) Biomarkers of toluene exposure in rats: mercapturic acids versus traditional indicators (urinary hippuric acid and o-cresol and blood toluene). Xenobiotica 43:651-660.

Guengerich FP (2011) Mechanisms of drug toxicity and relevance to pharmaceutical development. Drug Metab Pharmacokinet 26:3-14.

Haring B, Kudlich T, Rauthe S, Melcher R, and Geier A (2013) Benzbromarone: a double-edged sword that cuts the liver? Eur J Gastroenterol Hepatol 25:119-121.

Hautekeete ML, Henrion J, Naegels S, DeNeve A, Adler M, Deprez C, Devis G, and Klöppel G (1995) Severe hepatotoxicity related to benzarone: a report of three cases with two fatalities. Liver 15:25-29.

Hughes TB and Swamidass SJ (2017) Deep learning to predict the formation of quinone species in drug metabolism. Chem Res Toxicol 30:642-656.

Iwanaga T, Kobayashi D, Hirayama M, Maeda T, and Tamai I (2005) Involvement of uric acid transporter in increased renal clearance of the xanthine oxidase inhibitor oxypurinol induced by a uricosuric agent, benzbromarone. Drug Metab Dispos 33:1791-1795.

Kim KB and Lee BM (1997) Oxidative stress to DNA, protein, and antioxidant enzymes (superoxide dismutase and catalase) in rats treated with benzo(a)pyrene. Cancer Lett 113:205-212

Kitagawara Y, Ohe T, Tachibana K, Takahashi K, Nakamura S, and Mashino T (2015) Novel bioactivation pathway of benzbromarone mediated by cytochrome P450. Drug Metab Dispos 43:1303-1306.

Kobayashi K, Kajiwara E, Ishikawa M, Oka H, and Chiba K (2012) Identification of CYP isozymes involved in benzbromarone metabolism in human liver microsomes. Biopharm Drug Dispos 33:466-473. 
Lin G, Tang J, Liu XQ, Jiang Y, and Zheng J (2007) Deacetylclivorine: a gender-selective metabolite of clivorine formed in female Sprague-Dawley rat liver microsomes. Drug Metab Dispos 35:607-613.

Manger B (2015) Uricosuric agent benzbromarone vs. allopurinol: comparable effect. Dtsch Med Wochenschr 140:562.

McDonald MG and Rettie AE (2007) Sequential metabolism and bioactivation of the hepatotoxin benzbromarone: formation of glutathione adducts from a catechol intermediate. Chem Res Toxicol 20:1833-1842.

McEneny-King A, Osman W, Edginton AN, and Rao PPN (2017) Cytochrome P450 binding studies of novel tacrine derivatives: predicting the risk of hepatotoxicity. Bioorg Med Chem Let 27:2443-2449.

Moghe A, Ghare S, Lamoreau B, Mohammad M, Barve S, McClain C, and Joshi-Barve S (2015) Molecular mechanisms of acrolein toxicity: relevance to human disease. Toxicol Sci 143:242-255.

Nindita Y, Hamada T, Bahrudin U, Hosoyamada M, Ichida K, Iwai C, Urashima S, Kuwabara M, Utami SB, Mizuta E, et al. (2010) Effect of losartan and benzbromarone on the level of human urate transporter 1 mRNA [published correction appears in Arzneimittelforschung (2014) 64:103]. Arzneimittelforschung 60:186-188.

Poon GK, Chen Q, Teffera Y, Ngui JS, Griffin PR, Braun MP, Doss GA, Freeden C, Stearns RA, Evans DC, et al. (2001) Bioactivation of diclofenac via benzoquinone imine intermediates-identification of urinary mercapturic acid derivatives in rats and humans. Drug Metab Dispos 29:1608-1613

Quintanilha JCF, de Sousa VM, Visacri MB, Amaral LS, Santos RMM, Zambrano T, Salazar LA, and Moriel P (2017) Involvement of cytochrome P450 in cisplatin treatment: implications for toxicity. Cancer Chemother Pharmacol 80:223-233.

Stamp LK, Haslett J, Frampton C, White D, Gardner D, Stebbings S, Taylor G, Grainger R, Kumar R, Kumar S, et al. (2016) The safety and efficacy of benzbromarone in gout in Aotearoa New Zealand. Intern Med J 46:1075-1080.

Suzuki T, Suzuki T, Kimura M, Shinoda M, Fujita T, Miyake N, Yamamoto S, and Tashiro K (2001) A case of fulminant hepatitis, possibly caused by benzbromarone. Nihon Shokakibyo Gakkai Zasshi 98:421-425.
Tolosa L, Jiménez N, Pérez G, Castell JV, Gómez-Lechón MJ, and Donato MT (2018) Customised in vitro model to detect human metabolism-dependent idiosyncratic drug-induced liver injury. Arch Toxicol 92:383-399.

Wang H, Feng Y, Wang Q, Guo X, Huang W, Peng Y, and Zheng J (2016a) Cysteine-based protein adduction by epoxide-derived metabolite(s) of benzbromarone. Chem Res Toxicol 29:2145-2152.

Wang H, Peng Y, Zhang T, Lan Q, Zhao H, Wang W, Zhao Y, Wang X, Pang J, Wang S, et al (2017) Metabolic epoxidation is a critical step for the development of benzbromarone-induced hepatotoxicity. Drug Metab Dispos 45:1354-1363.

Wang K, Wang H, Peng Y, and Zheng J (2016b) Identification of epoxide-derived metabolite(s) of benzbromarone. Drug Metab Dispos 44:607-615.

Yang X and Bartlett MG (2016) Identification of protein adduction using mass spectrometry: protein adducts as biomarkers and predictors of toxicity mechanisms. Rapid Commun Mass Spectrom 30:652-664.

Yoshida M, Cho N, Akita $\mathrm{H}$, and Kobayashi K (2017) Association of a reactive intermediate derived from 1',6-dihydroxy metabolite with benzbromarone-induced hepatotoxicity. J Biochem Mol Toxicol 31.

Address correspondence to: Ying Peng, Wuya College of Innovation, Shenyang Pharmaceutical University, Shenyang, Liaoning 110016, P. R. China. E-mail: yingpeng1999@163.com; or Jiang Zheng, State Key Laboratory of Functions and Applications of Medicinal Plants, Key Laboratory of Pharmaceutics of Guizhou Province, Guizhou Medical University, Guiyang, Guizhou 550004, P. R. China.; Wuya College of Innovation, Shenyang Pharmaceutical University, 103 Wenhua Road, Shenyang, Liaoning 110016 P. R. China. E-mail: zhengneu@yahoo.com 